\title{
La estatua-menhir del Pla de les Pruneres (Mollet del Vallès, Vallès Oriental)
}

\author{
The Statue-Menhir from Pla de les Pruneres \\ (Mollet del Vallès, Vallès Oriental)
}

\begin{abstract}
Pablo Martínez Rodríguez
Arqueólogo. Miembro del Seminari d'Estudis i Recerca Prehistòrica (SERP), Universitat de Barcelona. pablomartrod@gmail.com
\end{abstract}

Recibido: $11-06-2010$

Aceptado: 27-02-2011

\begin{abstract}
RESUMEN
En el yacimiento del Pla de les Pruneres se ha encontrado una figura antropomorfa esculpida en tres dimensiones sobre un bloque de arcosa de 4,90 metros de altura y $6200 \mathrm{~kg}$ de peso. Resultan muy interesantes las similitudes que tiene esta estatua-menhir con las figuras de la Rouergue y el Languedoc francés, hecho que nos lleva a proponer una cronología para esta figura de 3300-2200 cal. BC., similar a la de estos grupos figurativos de Francia. Este descubrimiento se suma a la figura de Ca l'Estrada y el conjunto de Reguers de Seró que sitúan a Cataluña en primera línea de la investigación sobre arte megalítico del IV y III milenio.
\end{abstract}

Palabras Clave: Estatua-menhir. Estela antropomorfa. Neolítico. Calcolítico. Cataluña.

\begin{abstract}
At the site of the Pla de les Pruneres has been found an anthropomorphic figure carved in three dimensions on a block of arkose of 4.90 meters high and $6200 \mathrm{~kg}$ weight. The similarities of this statue-menhir with the figures of the Rouergue and the French Languedoc are very interesting, a fact which leads us to propose a timeline for this figure of 3300-2200 a.C. similar to these figurative groups of France. This discovery adds to the figure of Ca l'Estrada and the set of Reguers de Seró that place Catalonia in the forefront of research on megalithic art of the 4th and 3rd millennium B.C.
\end{abstract}

KeY WoRDs: Statue-menhir. Antropomorphic stele. Neolithic. Chalcolithic. Catalonia.

SUMARIO 1. Introducción. 2. El descubrimiento de la estatua-menhir y los trabajos realizados. 3. Descripción de la estatua-menhir. 4. Cronología. 5. Contexto histórico y paralelos. 6. Interpretación y conclusiones. 


\section{Introducción}

El descubrimiento de la figura del Pla de les Pruneres es la última aportación a una serie de hallazgos muy destacados efectuados en los últimos años que le dan a a Cataluña un papel propio en el mapa del arte megalítico de Europa.

La estatuaria antropomorfa megalítica es un documento arqueológico que nos aporta información y que nos ayuda a caracterizar a las comunidades neolíticas que esculpen estas grandes imágenes. De este modo se convierten en símbolos de referencia que son utilizados como grandes elementos de expresión por los grupos humanos que las producen y como símbolos de identificación por los mismos grupos que las levantan.

Las representaciones de estatuas-menhires se comienzan a encontrar en Europa a finales del IV milenio $\mathrm{BC}$ en la última etapa del Neolítico, se generalizan durante el III milenio y perduran en algunas zonas hasta la Edad de Bronce. La recurrencia de algunos elementos representados o de ciertos patrones iconográficos permite establecer, dentro del mapa del arte megalítico europeo, una serie de grupos escultóricos o figurativos. Por otro lado también se dan casos de estatuas-menhires aisladas como las de Ca l'Estrada o el Pla de les Pruneres que se han de estudiar en base a posibles relaciones de habitantes del Vallès con otros grupos culturales vecinos, hecho que comportaría la adopción de algunos elementos ideológicos importantes. Para este caso consideramos de gran interés los grupos de la Rouergue y Languedoc en la vecina Francia, con los que la estatua-menhir del Pla de les Pruneres guarda algunas similitudes, como podremos ver a continuación y con las que podremos proponer algunas interpretaciones y hacer hipótesis sobre la reconstrucción de la imagen original.

\section{2.- El descubrimiento de la estatua-menhir y los trabajos realizados}

El yacimiento se encuentra situado en la depresión prelitoral catalana, en el término municipal de Mollet del Vallès (Vallès Oriental), ubicado entre las calles Ramón Casas, la Pau, Rambla Pompeu Fabra y Anselm Clavé, en un paraje conocido con el topónimo del Pla de les Pruneres (Fig. 1).

Durante los trabajos de excavación de los rebajes mecánicos realizados en esta obra motivada por la construcción de un aparcamiento subterráneo, a mediados del mes de abril de 2009, se localizó este enorme bloque de piedra con grabados a más de 8 metros de profundidad. Un vecino de Mollet interesado por este descubrimiento, envió un mail a la empresa de arqueología Estrats G.P.C. con una foto preguntando por la naturaleza de aquella gran piedra con grabados. A continuación los arqueólogos y responsables de esta empresa se pusieron en contacto con el Servei d'Arqueologia de la Generalitat de Catalunya, le enviaron las fotos recibidas y le explicaron la situación de la obra. Este organismo, que se encarga de la gestión del patrimonio arqueológico en Cataluña, paralizó los trabajos y ordenó que se iniciase un proceso de investigación y excavación arqueológica en aquel lugar para localizar un posible contexto de esta pieza. El ayuntamiento de Mollet del Vallès, como promotor de la obra, encargó la excavación arqueológica de este nuevo yacimiento a la empresa Estrats G.P.C.

En ese momento, los trabajos a realizar sobre el yacimiento serían tratar de localizar el posible contexto de esta pieza, estudiar y documentar la estratigrafía en el punto donde se encontró la estatuamenhir, tratar de recoger restos materiales y orgánicos que nos permitieran establecer una cronología aproximada de esta pieza y para que nos ayudasen a reconstruir el paleoambiente de este espacio del Vallès Oriental en la prehistoria reciente.

Tras varias conversaciones con diferentes obreros y maquinistas de la obra supimos cómo se había localizado esta figura. El paquete de arcillas correspondientes a las capas O, P, Q, R y S (Fig. 2) había sido retirado en gran parte de una sola vez para rechazarlo pues no era un material útil. A continuación se procedió a rebajar las capas $\mathrm{T}, \mathrm{U}, \mathrm{V}, \mathrm{W}$ y $\mathrm{X}$ con materiales de piedras, gravas y arenas, muy útiles para procesar y reutilizar en posteriores obras. Estos rebajes de las capas $\mathrm{T}$ a $\mathrm{X}$ empezaron desde el extremo noroeste del aparcamiento hacia el sureste. En el punto indicado (Fig. 1, inferior) la máquina localizó, a unos 8 metros de profundidad, este gran bloque de arcosa. Debido a sus dimensiones y peso la máquina no lo pudo levantar y lo tuvo que arrastrar por encima de otras piedras y gravas, lo que le produjo numerosas marcas.

Los trabajos de excavación arqueológica realizados sobre una superficie aproximada de unos $1500 \mathrm{~m}^{2}$, se programaron con dos líneas de investigación. Por un lado delimitamos y protegimos un área de unos $40 \mathrm{~m}^{2}$ en el lugar donde se recogió la 
estatua-menhir. Esta área se excavó minuciosamente con un equipo de 5 arqueólogos durante 4 semanas para tratar de localizar cualquier material, resto biológico o elemento significativo que pudiese estar relacionado con la estatua-menhir.

Se coordenaron 24 elementos (cerámica, industria lítica, fauna y la propia estatua-menhir) que se encontraban en posición secundaria, se dibujaron cuidadosamente 2 perfiles (norte y este) de este espacio y se dibujaron también en planta algunas capas significativas.

Por otro lado y una vez observado que las diferentes estratigrafías que en ese momento podíamos estudiar nos remitían a un contexto de continuas aportaciones aluviales, de numerosos paleocanales y terrazas de rieras con muchas piedras, gravas, gravillas, arenas y muchas bolas blandas y bolas armadas en el resto del espacio del aparcamiento optamos por ir realizando rebajes con máquina controlados por un arqueólogo para localizar también algún material o contexto que se pudiese relacionar con la estatua-menhir.

Estos rebajes fueron especialmente controlados en la parte intermedia de la estratigrafía (entre los 5 a 7 m de potencia: capas O, P, Q, R y S, Fig. 2), donde se observaba en toda la extensión del yacimiento unas aportaciones de arcillas con la parte

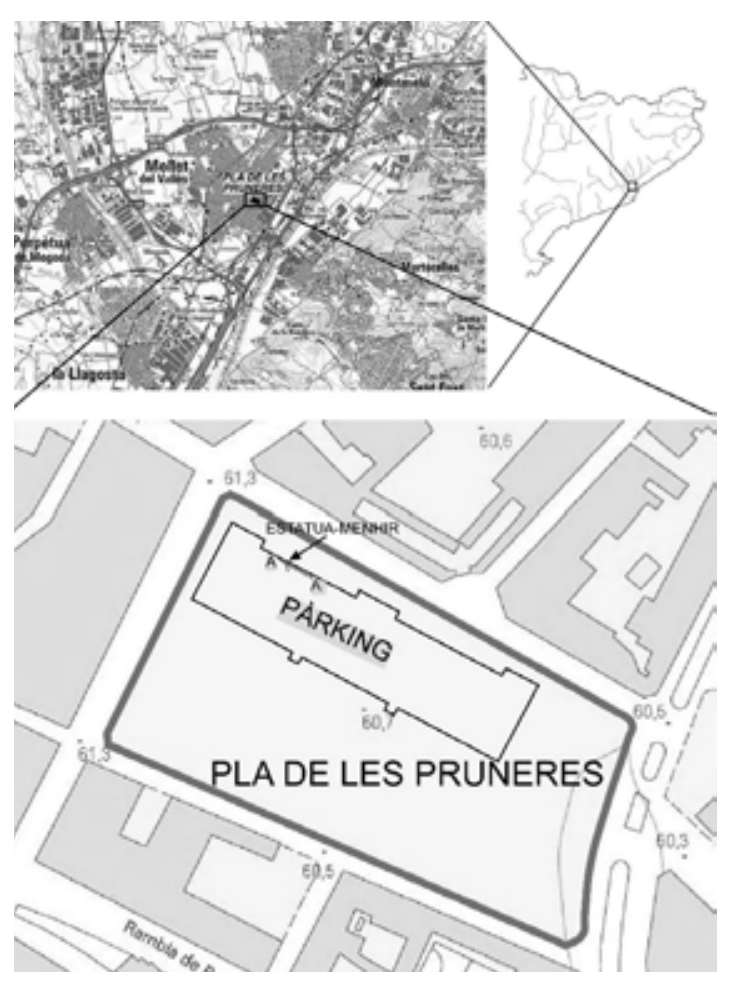

Figura 1.- Mapa de situación del yacimiento en Mollet del Vallès.

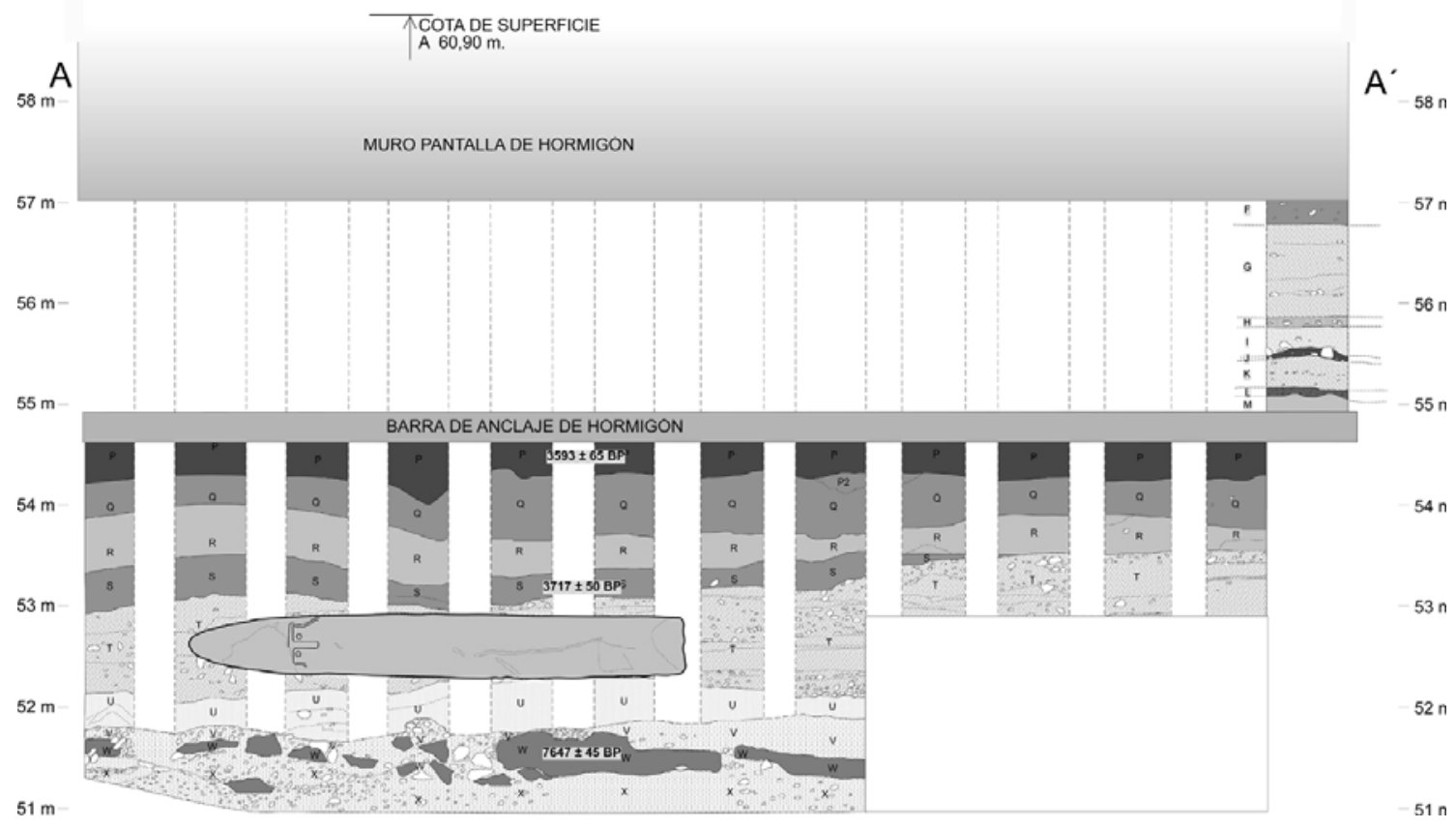

Figura 2.- Dibujo del alzado A-A' indicado en el plano (inferior) de la Figura 1. 
superior más oscura (capa P), las cuales presumiblemente eran un contexto más adecuado para tener algún resto de hábitat. Si bien el resto de la estratigrafía, por encima y por debajo de estas arcillas, testimoniaba una secuencia continua de episodios de rieras y terrazas fluviales, estas arcillas las interpretamos como un hiato o tiempo en el que las rieras no habían trabajado o estado actibas en este espacio, dando unas condiciones de hábitat más apropiadas.

Para tener controlada esta estratigrafía y poder testimoniar todos estos contextos aluviales, optamos por dejar unos perfiles verticales cada 10-15 metros, con diferente orientación, en los puntos donde nos parecía que podía ser interesante y siempre en coordinación con de los objetivos de las obras de este aparcamiento. Documentamos también fotográficamente todos estos perfiles y en los más interesantes el geólogo José Antonio Palazón realizó la descripción de numerosas columnas geológicas.

Con todos estos trabajos de control de los rebajes se recogieron algunos materiales (cerámicas, huesos, piezas de sílex) que resultaron poco numerosos y que se encontraban claramente en posición secundaria. Habían sido arrastrados por las continuas riadas que habían ido formando, después de miles de años, toda esta estratigrafía.

Se recogieron algunos materiales que podrían situarse en una cronología relativa. Entre ellos destacan una raedera de sílex (PPR'09-T-12) correspondiente a un Paleolítico Medio, un fragmento informe de cerámica con decoración cardial (PPR'09-T-18) correspondiente a un Neolítico Antiguo Cardial y un fragmento informe de cerámica con un cordón digitado (PPR'09-T-1) correspondiente a la Edad de Bronce. Todas estas cronologías están testimoniadas en yacimientos situados a pocos kilómetros alrededor de Mollet (Martín 2006), destacando con relevancia la concentración que vemos en el término municipal de Sta. Perpètua de la Mogoda. La gran acumulación de yacimientos refleja la recurrencia de ocupación del Vallès en cronologías prehistóricas.

Con todo, no encontramos ningún material o estructura arqueológica relacionable con la estatua-menhir y toda la estratigrafía nos remite a materiales aportados en posición secundaria por los diferentes episodios de riadas.

El estudio geológico realizado por José Antonio Palazón (2010) nos indica que esta zona ha estado ocupada hasta hace pocos años por dos rieras. Los sedimentos observados son en su mayoría granulares, gravas y arenas, producto de los aluviones de las rieras que se han ido depositando en estratos o capas lenticulares que se erosionaban unas a otras. Encontramos estructuras sedimentarias en diferentes direcciones, hecho que nos indica que han funcionado cursos de agua en diferentes orientaciones, posiblemente debido a la existencia de una red de canales trenzados, además de la confluencia de dos rieras en este punto, así como la influencia del río Besós.

La base de la obra coincide con un nivel de materiales finos posiblemente de origen palustre (mucha materia orgánica reducida, arcilla muy plástica) que se interpreta como una zona de pantanal, ligada a la llanura de inundación del Besós. La serie de sedimentos granulares con tendencia granodecreciente marca una pequeña secuencia deposicional ligada a cambios climáticos. Son sedimentos de aluviones que se dan durante las etapas de clima frío con lluvias torrenciales. Los sedimentos más finos corresponden a períodos donde el régimen de lluvias es más continuo y no hay avenidas de materiales gruesos desde las rieras. Estos depósitos concuerdan con planas de inundación y zonas de morfología muy plana donde se mantendría una pequeña lámina de agua. Estos periodos están más relacionados con los aportes procedentes del río Besós.

Por otro lado, en la profundidad en la que apareció la estatua-menhir, encontramos acumulaciones de materiales disgregados, gruesos, propios de rieras que aportan mucho material durante avenidas fuertes, hecho que denota un clima dominante por lluvias catastróficas. Normalmente estas lluvias van ligadas en nuestro entorno a épocas de clima frío y árido. En estos periodos en la zona dominan los aportes de las rieras.

\section{Descripción de la estatua-menhir}

Las dimensiones del bloque de arcosa, con 490 $\mathrm{cm}$ de altura, $69 \mathrm{~cm}$ de ancho y $110 \mathrm{~cm}$ de profundidad, hacen de esta figura la estatua-menhir más grande de toda Europa.

El bloque de arcosa que es el soporte de la representación ha sido repicado en toda su superficie, desde la base inferior hasta la punta superior (Figs. 3 y 4). Este hecho nos indica que todo este 

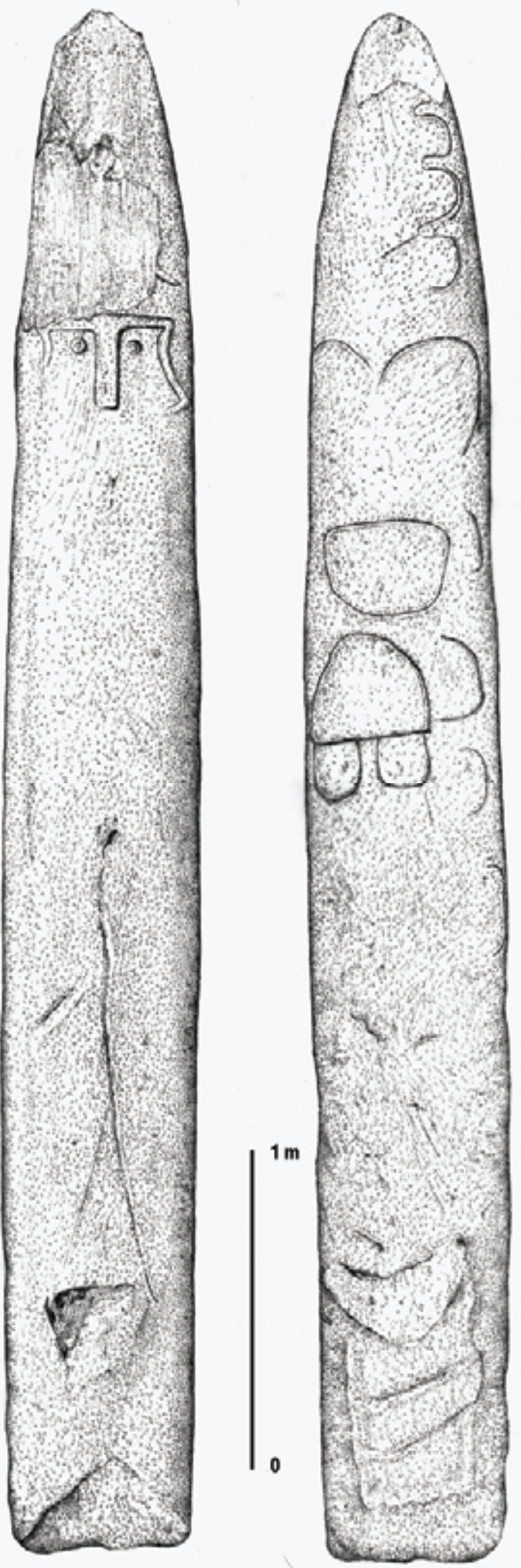

Figura 3.- Dibujo de las caras frontal y dorsal de la estatua-menhir del Pla de les Pruneres (Aida Alarcos).

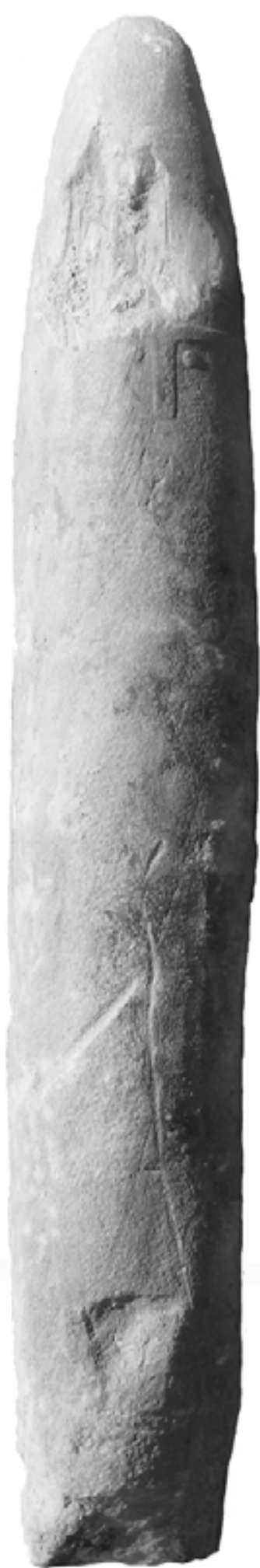

Figura 4.- Fotografía completa de la estatua-menhir del Pla de les Pruneres.

Complutum, 2011, Vol. 22 (1): 71-87 
trabajo de repiqueteo se ha realizado con la pieza situada horizontalmente, antes de ser colocada de forma vertical.

Una de las cuestiones más interesantes es por qué tiene decoradas las caras estrechas de la piedra y no las caras más anchas, con más espacio para recoger toda la representación. En el resto de Europa vemos que siempre las decoraciones están situadas sobre las caras más anchas y este es el único caso donde se ha esculpido la cara frontal y dorsal sobre las caras más estrechas de la piedra. Una posible explicación vendría dada por el hecho de que el trabajo escultórico se realizó con la piedra tumbada lateralmente y apoyada sobre una de las caras anchas, pudiendo trabajar así las dos caras frontal y dorsal. De otra forma, podían haber decorado una de las caras anchas de la piedra, darle la vuelta, y decorar la otra cara. Sabemos que darle la vuelta a la piedra les era posible pues ya lo habían hecho para repicar toda la superficie anteriormente.

La técnica escultórica que vemos en las dos caras trabajadas es diferente. Los motivos de la cara delantera están realizados en bajorrelieve, dejándolos en positivo, y con una técnica muy fina y detallada. En la cara posterior en cambio los motivos están realizados por repicado y posterior abrasión, dejando los motivos en negativo, con una técnica más sencilla (Fig. 3).

En la parte frontal de la pieza encontramos esculpida la cara de la figura con la representación de la clásica " $T$ " facial (Figs. 4 y 5). Se encuentran esculpidos los dos ojos a lado y lado de un relieve vertical que representa la nariz. Encima de ésta, unida a ella pero dispuesta de forma horizontal y con un pequeño arqueamiento hacia arriba, encontramos representadas las dos cejas.

La representación de la clásica " $T$ " facial es propia de las figuras del grupo Languedociano (D'Anna 1977), aunque se encuentra también en estatuas-menhires situadas en diferentes geografías europeas como la representación de Villar del Ala en Soria (Romero 1981), Dolmen de Soto en Cádiz (Bueno 1990, Almagro Gorbea 1993), o diversas figuras de la Provenza, los Alpes, grupo de Lunigiana o figuras de Cerdeña (Arnal 1976). Cabe señalar que esa cara tan regular o geométricamente ordenada, no se encuentra en el Languedoc, y sólo la hemos encontrado en algunas placas alentejanas datadas a finales del IVto y primera mitad del III'r milenio (Gonçalves 2004, 8), que resultan, por su tamaño, muy alejadas de este gigante.

Este hecho no es una cuestión baladí pues el trabajo escultórico es tan minucioso y la perfección es tal que se han llegado a esculpir incluso los iris en el centro de los ojos (Figs. 5 y 6). Todo esto nos hace pensar en el trabajo de un especialista o de una persona con mucha experiencia. Pero no sólo experiencia en escultura sobre piedra, sino un conocimiento de este tipo de representaciones, de cuáles son los motivos que se eligen para representar, cómo se organizan esos motivos, cómo se orientan, cómo se dimensionan, etc...

En la representación de las cejas, en sus extremos a lado y lado, encontramos unos elementos representados que bajan verticalmente de forma curvada hacia el exterior y que, en su extremo inferior, giran bruscamente hacia el interior. Este último elemento descrito sólo se ha conservado bien en el lado izquierdo de la cara (Figs. 5 y 6 ) porque en el lado derecho, la erosión de los episodios aluviales que arrastraban piedras y gravas por encima de esta cara, una vez la estatua-menhir ya estaría tumbada en tierra, ha erosionado mucho este motivo. Con todo, lo hemos podido identificar en algunas fotografías realizadas a la estatua-menhir. La observación detallada con juegos de luces y sombras permite ver que aún se aprecia una parte de este motivo, aunque muy mal conservado. De hecho resulta incluso imperceptible en condiciones de luz naturales.

Sin duda pensamos que estos elementos no forman parte de ningún elemento de la cara pues son más estrechos que los otros rasgos faciales representados. Los interpretamos como la representación de los brazos que, dispuestos verticalmente, bajan paralelamente a lado y lado de la cara (Figs. 5 y 6). La representación de estos brazos en este punto, con esta orientación, dimensiones y morfología, la encontramos también de forma muy similar en el Languedoc en figuras como MaisonAube, Collorgues y Rosseironne (Arnal 1976; D'Anna 1977 y 2002). Por estos paralelos del Languedoc sabemos que a continuación de estos brazos y después del giro hacia el centro de la estatua, se encuentran esculpidas las manos. Aunque estos rasgos morfológicos no se identifican en la figura del Pla de les Pruneres, el resto de los elementos conservados nos llevan a proponer que debían haberse esculpido y que, desgraciadamente, 


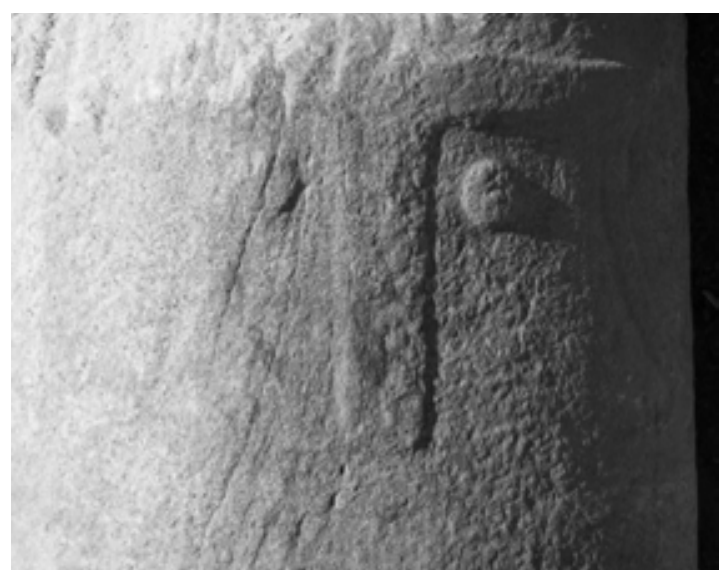

Figura 5.- Fotografía de detalle de la cara de la estatuamenhir del Pla de les Pruneres.

los procesos erosivos los han borrado y se han perdido.

Encima de las cejas encontramos uno de los agujeros realizados por los pilotajes iniciales para hacer las paredes del aparcamiento. Este agujero realizado por un taladro de unos $55-60 \mathrm{~cm}$. de diámetro (Figs. 2 y 3), perforó y recortó la figura en los trabajos iniciales de la obra cuando todavía la estatua-menhir estaba enterrada a 8 metros de profundidad. Estos pilotajes formaban las paredes de la obra y ayudaban a mantener los perfiles rectos para poder hacer los rebajes en su interior de forma controlada. Aunque la distancia entre cada uno era de 1 metro, la estatua-menhir fue perforada y parcialmente destruida por dos de estos pilotajes.

El agujero de la cara frontal nos ha hecho perder otro elemento esculpido que se encontraba representado sobre las cejas y del que solo se conserva un pequeño tramo de unos $5-6 \mathrm{~cm}$ a unos $12 \mathrm{~cm}$ por encima de la ceja izquierda de la figura (Fig. 6). Es en figuras como Maison-Aube (Gard, Francia) o le Bon Diablet (Vall d'Alzon, Francia) donde podemos ver como encima de las cejas también tienen esculpido un motivo de forma horizontal. La destrucción de la estatua-menhir en este punto dificulta la interpretación de este elemento y nos hace imposible reconocerlo, pero el estudio de las piezas languedocianas nos lleva a interpretar que simplemente se podría tratar de la representación de una línea que cerraría la cabeza por la parte superior. Con todo y aunque los elementos representados en la estatuaria megalítica europea son muy recurrentes en morfología, dimensiones y
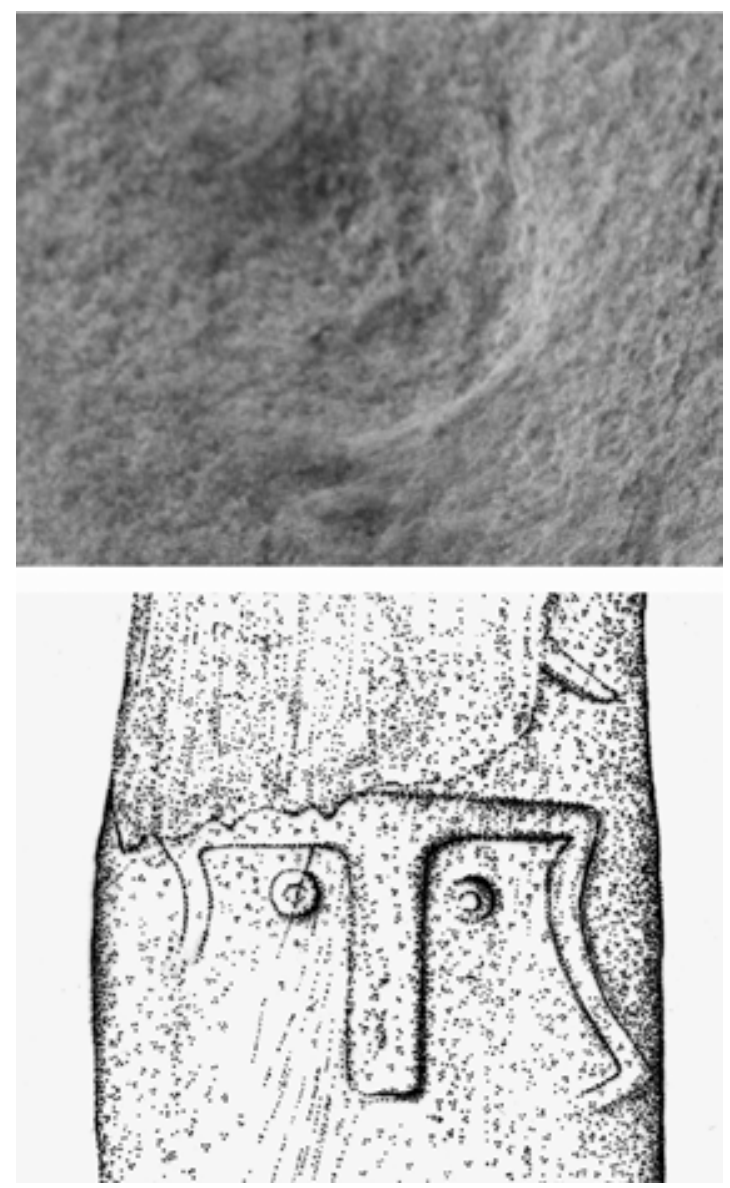

Figura 6.- Arriba: fotografía de detalle del ojo izquierdo de la estatua-menhir del Pla de les Pruneres. Abajo: ampliación del dibujo con detalle de la cara de la estatua-menhir del Pla de les Pruneres (Aida Alarcos).

orientaciones, podría tratarse de algún otro elemento que desconocemos. Sólo el descubrimiento de más figuras en la zona de Cataluña nos podría aportar luz en este punto, pues posiblemente podría tratarse de un elemento aparecido sólo en las figuras catalanas.

En el resto de la cara frontal de la pieza no hemos encontrado ningún otro elemento esculpido, si bien sí que hay otras marcas producidas por la máquina retroexcavadora (Figs. 3 y 4) que arrastró la piedra en el yacimiento por encima de otras piedras y gravas antes de la intervención arqueológica y que quedarán como parte de la historia de la pieza.

Aunque en el resto de la estatuaria megalítica europea en las caras posteriores de las figuras 

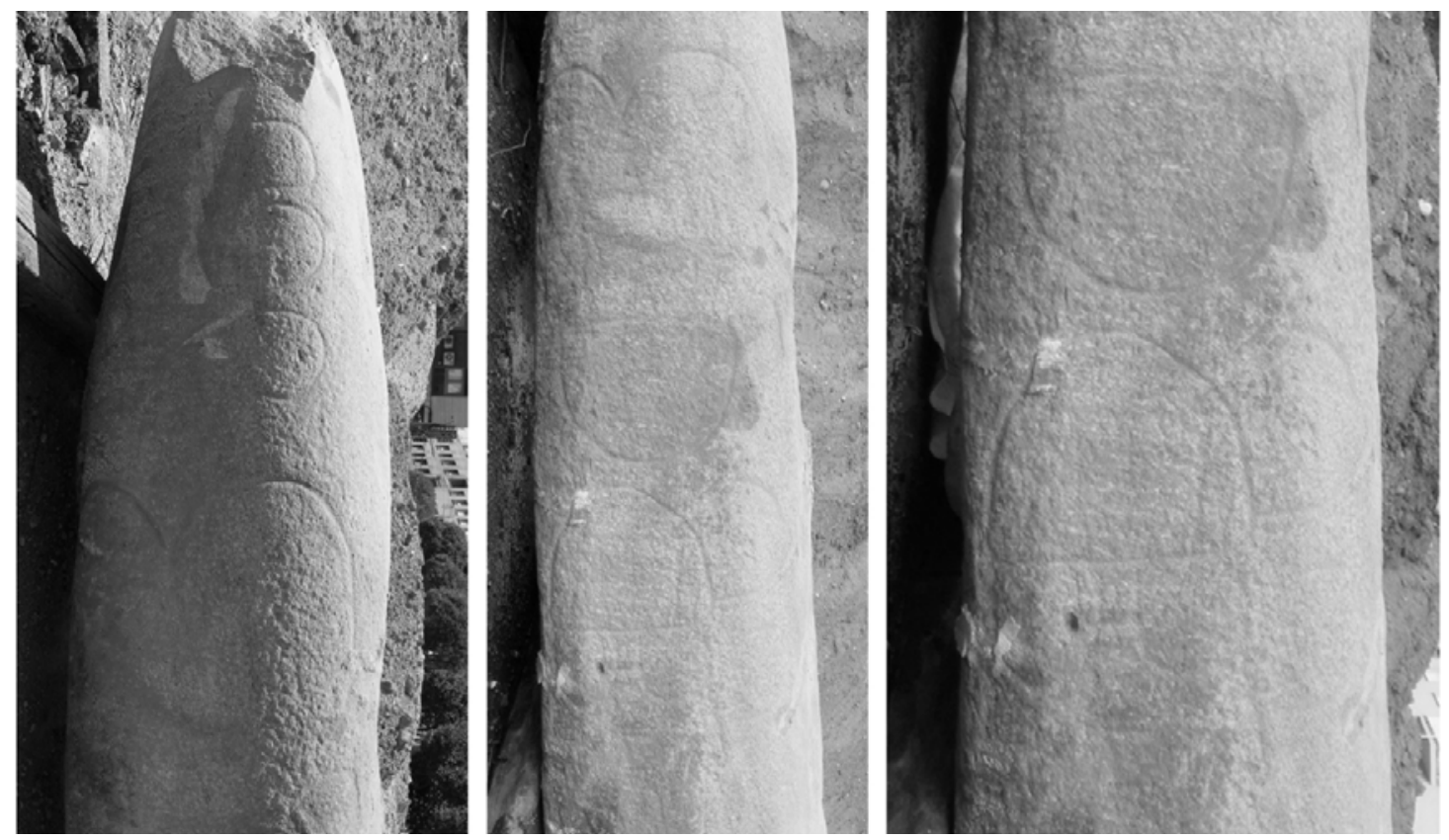

Figura 7.- Fotografías de detalle de los motivos esculpidos en la cara dorsal de la estatua-menhir del Pla de les Pruneres.

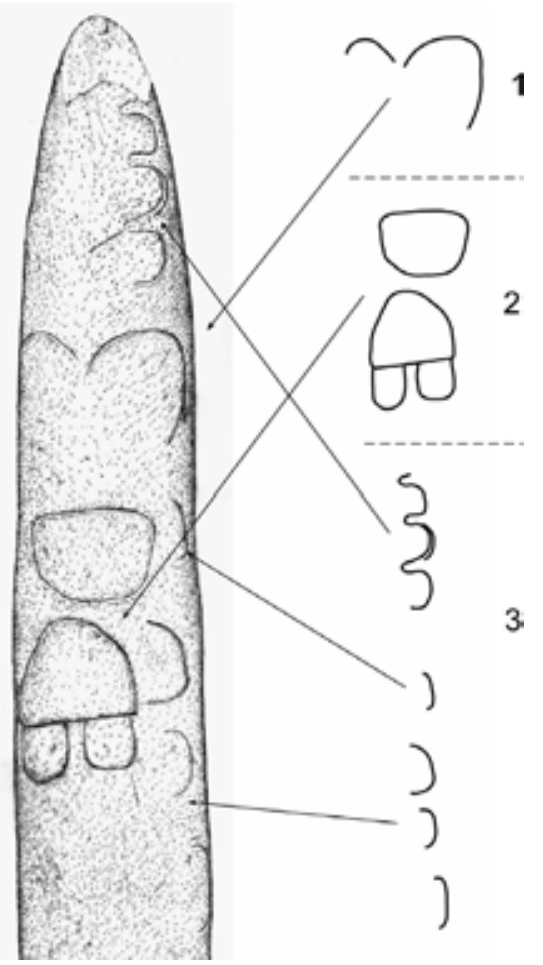

Figura 8.- Dibujo de la cara dorsal de la estatua-menhir del Pla de les Pruneres con las agrupaciones de motivos 1,2 y 3 , que se encuentran esculpidos. encontramos una serie de motivos que parecen más repetitivos, en la cara posterior de esta pieza tenemos una serie de motivos representados que son más difíciles de interpretar.

Los únicos elementos que reconocemos de esta parte posterior son dos grandes líneas curvas que, situadas a la misma altura de la cabeza en esta parte posterior, quieren formar dos elementos simétricos que hacen una representación conjunta en forma de "M" con los ángulos superiores curvados. Este motivo que hemos agrupado con el número 1 (Figs. 7 y 8), lo identificamos como la representación de los dos omoplatos, elementos o rasgos morfológicos que se encuentran únicamente esculpidos en las estatuas-menhires del grupo de la Rouergue en el Aveyron (Serres 1997, Philippon 2002).

Los grabados que hemos agrupado con el número 2 (Figs. 7 y 8) nos resultan de muy difícil interpretación. No hemos encontrado ningún motivo parecido en ninguna otra estatua-menhir de Europa. Lo único que hemos visto que pudiera relacionarse sería el esquema de organización, la ordenación de los motivos, localizados en algunos ortostatos decorados como el número 9 de Gavrinis (Shee Twohing 1981) en la Bretaña francesa. Sin duda este paralelo resulta muy lejano y nos resulta muy extraño encontrar aquí alguna relación. 
En referencia a los dos apéndices inferiores que sobresalen en esta agrupación número 2 (Figs. 7 y 8), Jean Guilaine nos apuntaba a un detalle parecido que se encuentra en las estelas 8,18 y 23 de Petit Chasseur y que había sido interpretado por nuestros colegas suizos como bolsas que colgarían del cinturón o faja (Gallay 1995; Corboud/Curdy 2009). Si bien en esas figuras este motivo aparece en la cara delantera de las mismas, no vemos clara esta relación y únicamente lo exponemos a modo de información.

De hecho los motivos decorados que encontramos en la cara posterior de estatuas-menhires de la Rouergue, algunas figuras alpinas, figuras portuguesas y las mismas representaciones de Reguers de Seró (López et al. 2009), nos remiten a piezas de ropa del tipo abrigos o sobretodos. Los sobretodos que vemos en diferentes figuras europeas tienen su prueba arqueológica en el hombre de los hielos conocido como Ötzi (Spindler 1995) y estaba formado por una capa de elementos vegetales atados cuidadosamente que se sobreponían al abrigo formado por piezas rectangulares de cuero cosidas, pieza que se ha identificado posteriormente en las estelas de Reguers de Seró (López et al. 2009).

$\mathrm{Si}$ todas las representaciones europeas parece que siguen unos esquemas en la elección, morfología, dimensiones y orientación de los motivos representados, creemos que estos motivos de la figura aquí estudiada agrupados con el número 2 (Figs. 7 y 8 ) podrían representar algún elemento de ropa que desconocemos. Si apuntamos que esta teoría es solo una propuesta, tendremos que esperar a futuros descubrimientos e investigaciones que aporten luz a este tema.

Los grabados agrupados en el número 3 (Figs. 7 y 8) también nos resultan difíciles de interpretar. No hay paralelos en estatuas-menhires como tales, si bien la estela de la Vila de Llanera (Llanera, Lleida) (Serra Vilaró 1927; Moya et al.2010) presenta unos motivos parecidos en uno de los laterales. En ese caso, la zona donde se encuentra, la cronología propuesta y la localización y disposición de los propios motivos en la estela sí que nos ha llevado a proponer una interpretación (López et al.2010, Martínez en prensa) que no sería la misma que para la figura del Pla de las Pruneres. Así, nos encontraríamos ante una conjunción formal, donde un mismo motivo ha querido representar dos realidades diferentes.

También hemos encontrado estos motivos en monumentos como la estela de Pola de Allande (Asturias) (de Blas Cortina 1997) o en Pierre Plats (Carnac) (Shee Twohing 1981). Aunque estos motivos tienen un aire atlántico, no resultan extraños en Cataluña pues aquí tenemos manifestaciones consideradas también como atlánticas en la estela del Pla de la Calma (Montseny) (Vilardell y Castells 1976; Moya et al. 2010), la estela del Puig Castellar (Sant Vicenç dels Horts) (Ripoll et al. 1965; Anguas et al. 2006) o la representación espiraliforme de Albi (Les Garrigues) (García et al. 2003).

Las diferentes técnicas escultóricas utilizadas en las dos caras decoradas de esta figura nos proponen quizás dos momentos en su escultura. El primero sería sin duda la $\mathrm{T}$ facial de la cara delantera realizada en bajorrelieve, que podría seguir una tradición, una idea formal ampliamente extendida que encontramos en muchas estatuas-menhires europeas y estrechamente relacionada, en este caso, con las figuras Languedocianas. Los grabados de la parte posterior, realizados por simple repiqueteo, podrían ser posteriores, desde unos años hasta unos siglos más tardíos.

Cabe valorar también el hecho de que estos grabados de la cara posterior sean contemporáneos a los de la cara frontal, pero realizados por diferentes personas. Esta opción estaría apoyada por el hecho de que los motivos agrupados con el número 3 (Figs. 7 y 8 ) solo están en el lado derecho de la cara posterior y que, de los dos motivos agrupados con en número 1 , el motivo de la derecha sí que se prolonga hacia abajo pero no así el motivo de la izquierda. Esta observación vendría a proponer que estos motivos se esculpieron con el bloque de arcosa tumbado sobre su lado izquierdo, hecho que habría imposibilitado al/los artistas trabajar en esa zona de la figura.

En relación al origen de la piedra sobre la que se esculpe la estatua-menhir, el estudio realizado por los geólogos Marius Vendrell, Pilar Giráldez y Lorena Merino $^{2}$ nos remite a una arcosa, una roca sedimentaria formada por la erosión de materiales graníticos. Sobre la localización del lugar de origen del bloque, estamos estudiando dos posibilidades. Estos compañeros nos apuntan que este bloque podría provenir de la erosión y sedimentación de los granitos de la serralada Litoral, a escasos 34 kilómetros al sureste del yacimiento donde fue descubierta la figura.

Por otro lado, una segunda opinión aportada por 
un geólogo de Mollet conocedor de la geología y petrografía de la zona, abre la posibilidad de que este bloque provenga de la serralada Prelitoral, de una zona al norte entre Caldes de Montbui y Bigues i Riells, a unos 11-13 kilómetros de distan$\mathrm{cia}^{3}$. Este bloque podría haber sido transportado puntualmente en diferentes episodios geológicos de grandes riadas, aunque su peso y dimensiones no apoyan esta teoría. En otra línea podría haber sido transportado desde aquella distancia con los medios de la época, consistentes en tirar con cuerdas de la piedra situada sobre troncos, arrastrándola así hasta el lugar deseado en el centro del actual Mollet del Vallès.

\section{Cronología}

En este yacimiento hemos podido datar la capa "S" que es la que cubría la capa "T" donde se encontró la estatua-menhir. La datación de un carbón de este estrato "S" ha proporcionado una data-

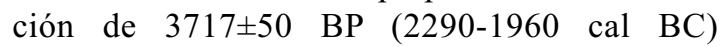
(LTL4375A), por lo que se confirma la propuesta de situar esta representación en el IIIer milenio a.C. además de probar que la figura cayó o se tiró al suelo y por tanto perdió ya todo su simbolismo, también antes de esta datación.

Los estudios que se han realizado en Europa sitúan las estatuas-menhires en el cuarto, tercer y segundo milenio a.C. Estas cronologías se han establecido muy pocas veces por contextos arqueológicos claros y relaciones directas con materiales y dataciones de C14. En la mayoría de casos, estas figuras no se encuentran in situ, y cuando así es, no presentan casi nunca un contexto asociado. De esta forma hemos de recurrir a estudios paralelos, presencia o ausencia de elementos identificables como puñales remedello o puñales de lengüeta, o interpretaciones del todo discutibles, para poder situarlas en algún momento de nuestra prehistoria.

Los paralelos con los grupos figurativos de la Rouergue y Languedoc y algunas dataciones de C14 nos llevan a situar esta estatua-menhir de Mollet entre el 3300 y el 2200 a.C. Si bien la cronología del Neolítico Final en Cataluña está establecida desde un 3500 a.C. (Martín 2003; Martín y Mestres 2003), consideramos una fecha de 33003200 a.C. como la cronología inicial más adecuada e incluso podría ser algo posterior, pues esta figura muestra claras similitudes con las del Midi francés, donde estas representaciones tuvieron mucha difusión y, a priori, debieron ser un poco más antiguas.

La datación final que estaría entre 2400-2200 a.C. difiere un poco de los grupos franceses por el hecho destacado de que, de momento en Cataluña, el fenómeno de la estatuaria megalítica no parece tener tanta fuerza ni tanta entidad como en los grupos de la vecina Francia. A esto le añadimos la aparición de los materiales campaniformes hacia el 2700-2600 a.C., que según pensamos llevarían asociados unos nuevos rituales y creencias referidas al mundo funerario y religioso. Así creemos que en pocas generaciones podríamos encontrar un cambio o asimilación de nuevas creencias que dejarían fuera de lugar estas representaciones, hecho que podría ser una de las explicaciones del contexto hallado con las estelas de Reguers de Seró (López et al. 2009).

\section{Contexto histórico y paralelos}

La zona de la Serralada Litoral y Depresión Prelitoral en los alrededores de Mollet ha sido objeto de algunos estudios en los últimos años sobre alguno de los monumentos o sobre un pequeño conjunto de esta zona (Bassols et al. 1995; Cura 2002-2003; de Marfà 2005).

En el análisis bibliográfico que hemos hecho, hemos localizado 48 monumentos megalíticos pertenecientes a estas geografías dentro de las comarcas del Vallés Oriental y Maresme. Estos monumentos responden a una rica variedad tipológica que engloban dólmenes, galerías catalanas, paradólmenes, menhires, crómlechs, rocas perforadas, rocas con insculturas y estatuas-menhires.

Si bien ya conocíamos la presencia de diversos dólmenes en este territorio, ha sido una sorpresa encontrar en este proceso de documentación hasta 16 menhires, aunque alguno resulta dudoso. Alrededor del yacimiento del Pla de les Pruneres tenemos referencia de la existencia de diversos monumentos megalíticos como la Pedra Salvadora en Mollet, el dolmen y el menhir de Castellruf en Santa Maria de Martorellas, la Pedra de Llinás situada en Montmeló, la Pedra Serrada en Parets del Vallés, el dolmen de can Traïdor en Gàllecs y la Pedra Llarga, la Pedra de can Falguera y la de can Tarragona en Palau (Ansó y Campoy 2007). También tenemos restos de hábitats contemporáneos a este hallazgo de Mollet, en cronologías de 
Neolítico Final, en el campo de fútbol de Montmeló y en Can Vinyals, Escoles Nacionals, Can Vinyalets II y Can Filuà en Sta. Perpètua de la Mogoda.

El panorama de estudios del arte megalítico en Cataluña por lo que se refiere a estatuaria de gran formato ha cambiado mucho en los últimos años. Si bien hace una década se advertía que la marginalidad del arte megalítico catalán era solo aparente, causada por los déficits de la investigación (Bueno/Balbín 2000), diez años después este panorama ha cambiado completamente y así se hace referencia en la investigación actual (Bueno et al. 2007; 2009; 2010).

Las aportaciones más actuales y sorprendentes provienen desde el 2004 de la arqueología preventiva. Éstas han permitido situar Cataluña en el mapa de la estatuaria antropomorfa del Neolítico final-Calcolítico (Fig. 9) y hacerlo, además, con voz propia (Moya et al. 2010)

El paralelo más próximo de la figura aparecida en Mollet lo tenemos en la ya conocida estatuamenhir de $\mathrm{Ca}$ 1'Estrada (Canovelles, Vallés Oriental) (Fortó et al. 2005, 2006, 2007 y 2008, Martínez et al., en prensa). Se trata del paralelo más cercano tanto por geografía y cronología como sobretodo por las propias características e interpretación de la pieza.

Otros paralelos en Cataluña serían las estelas de Reguers de Seró (Seró) (López et al. 2009), Bassa del Boix (Llobera), Gangonells y Roc de la Mare de Déu (Pinell) (Serra Vilaró 1927; Moya et al. 2010), a las que se suman unos fragmentos de una figura similar identificados recientemente en Arbolí (López et al. 2009; Moya et al. 2010)Todas estas figuras han sido recogidas recientemente en lo que se ha dado en llamar grupo escultórico de Seró (López et al. en prensa).

También antropomorfo sería el menhir del Coll del Cantó (Vidal 1911; Jiménez 2006) y la estela de la Vila de Llanera (Llanera) (Serra Vilaró 1927). Hemos visto una posible representación femenina en la estela de la Sitja del Llop (Montseny) (Moya et al. 2010) y un reciente estudio sobre las estelas de Passanant (Moreau 1970, Cura 1992) nos lleva a pensar que, aunque anteriormente una de ellas había sido considerada también como una figura femenina, las insculturas de las caras laterales (Moya et al. 2010) nos hacen disentir de esa idea y esperamos futuros estudios nos puedan ayudar a descifrar esos grabados. Más tardía sería ya la este- la de Preixana (Preixana, Lleida) (Maluquer 1971) perteneciente a la Edad de Bronce.

En el resto de Europa existen otras zonas con multitud de estatuas-menhires y estelas (Fig. 9) que presentan algunos elementos o atributos esculpidos similares a esta figura. El estudio de la presencia/ausencia de esos motivos, sus dimensiones, localización y orientación dentro de la figura esculpida (Arnal 1976; D’Anna 1977; Landau 1977; Shee Twohing 1981; Bueno 1990; AA.VV. 1994; Belley et al. 1998; Philippon 2002; D'Anna/Renault 2004) nos ha hecho avanzar mucho en la interpretación de los propios motivos y en la identificación de otras imágenes fragmentadas o erosionadas.

\section{Interpretación y conclusiones}

El tema de la interpretación o significación de estas representaciones es muy difícil de afrontar.

Podemos proponer algunas hipótesis, algunas de las cuales están apoyadas en datos arqueológi$\cos$, junto con otras que vienen justificadas por paralelos etnográficos.

Como ya se ha expuesto en otros trabajos parece que existía un idea general de cómo se representaban estas figuras (Robb 2009). Así podemos encontrar en esta estatua-menhir de Mollet una serie de elementos comunes a otras figuras de la Península Ibérica y resto de Europa occidental, pero que resultan de carácter genérico. Con todo y yendo más al detalle, hay una serie de elementos que se encuentran compartidos con otras estatuasmenhir del sureste de Francia. Así exponemos que el motivo 1 de la decoración dorsal de esta figura lo encontramos en representaciones de la Rouergue en lo que los compañeros franceses llamaban "crochets-omoplates" (Serres 1997) que después se han considerado simplemente terminación dorsal de los brazos (Maillé 2010). Del mismo modo, la representación de la cara parece compartir muchas similitudes con las figuras del Languedoc y de forma similar, la interpretación que hacemos de esos apéndices laterales y su giro cerrado hacia el interior, nos llevan a proponer una representación estrechamente relacionada con las Languedocianas.

Únicamente el motivo 3 de la decoración dorsal, con una estética que se podría considerar atlántica, nos remite a paralelos del oeste de la península ibérica. Con todo, esto no resulta algo aislado en 


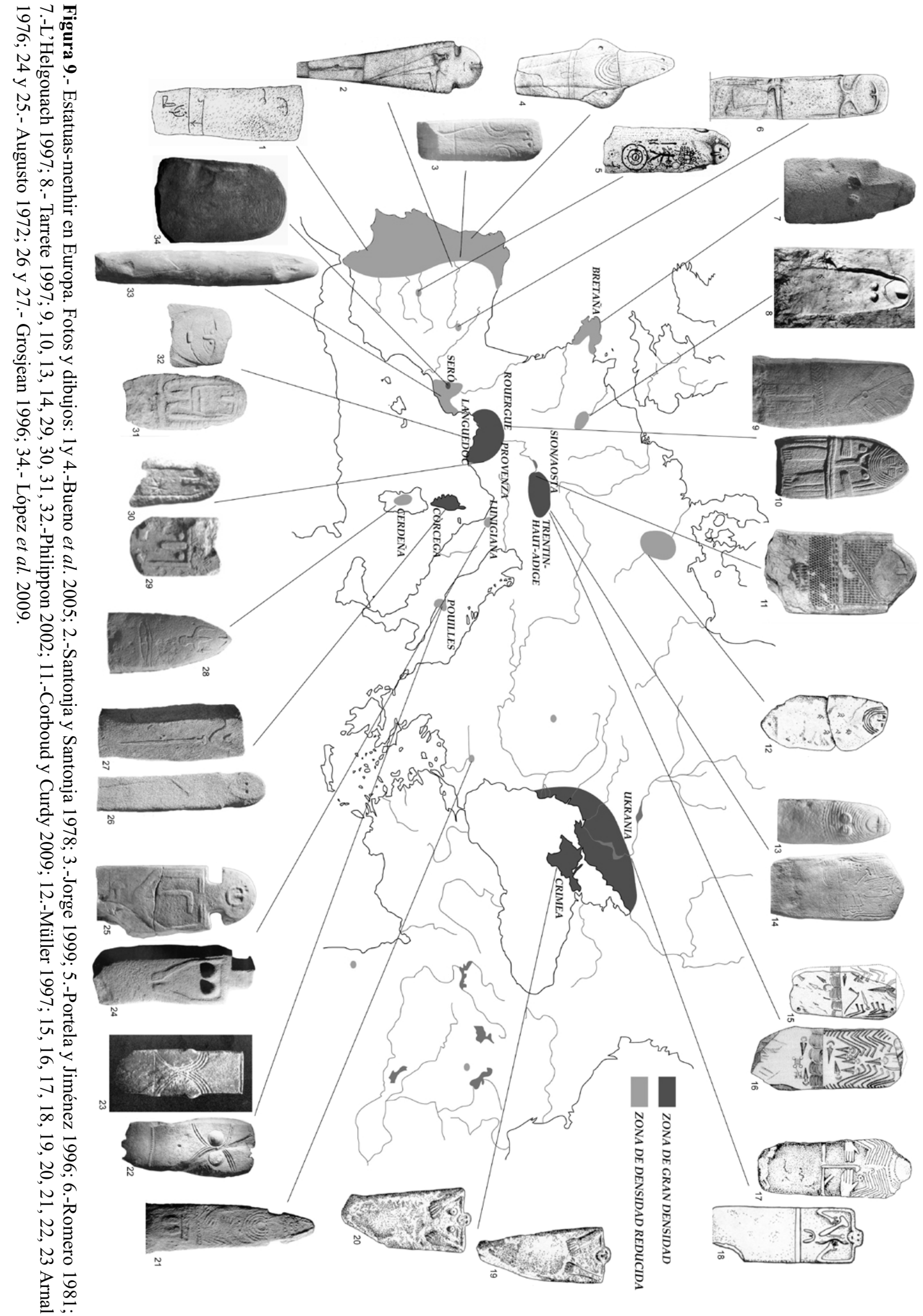

Complutum, 2011, Vol. 22 (1): 71-87 
Cataluña (Bueno 2009), considerando que hemos hecho aportaciones interesantes con las figuras de la Sitja del Llop, Passanant y Llanera (Moya et al. 2010) que pueden abrir nuevos enfoques.

La cultura material nos indica que durante las cronologías de la prehistoria reciente Cataluña está intensamente ligada al sureste de Francia. Así nos atreviríamos a sugerir que de hecho los Pirineos no resultan un elemento que separe afinidades y que esa línea de ruptura, o ese elemento que separa diferencias, parece encontrarse más cerca del Ebro. No ha de resultar pues chocante que también en lo referido a arte, encontremos los paralelos más próximos en estas geografías cercanas del norte y en menor proporción o casos aislados en el resto de la Península Ibérica.

Aunque hay pocos casos donde se encuentre un contexto que nos ayude a interpretarlas, cuando es así las estatuas-menhires y estelas antropomorfas se encuentran en tres contextos diferentes: en plena naturaleza, hábitat y necrópolis, hecho que podría implicar la existencia de significados diferentes.

En el yacimiento de Ca l'Estrada (Canovelles, Vallès Oriental) encontramos un importante yacimiento neolítico con una estatua-menhir que, si bien no estaba in situ, sí que pensamos que era cerca del lugar original, con un contexto arqueológico para estas cronologías de Neolítico final muy destacado. Las estructuras de combustión de grandes dimensiones y el recinto de fosos localizados a escasos metros de donde recogimos la estatuamenhir, nos lleva a pensar en un espacio con unas connotaciones especiales donde podrían celebrarse encuentros o ceremonias de tipo religioso (Fortó et al. 2005 y 2008; Martínez 2010, Martínez et al. en prensa).

En el grupo de la Rouergue las encontramos en medio de bosques, de esta forma podrían ser señales que marcaran algunos ejes o caminos, que actuaran como guías con apariencia humana. Estas figuras podrían representar esas personas que conocían el bosque y que una vez éstos hubieran desaparecido, las estatuas-menhires los simbolizarían y perpetuarían su conocimiento (D'Anna 1977).

En el Languedoc es destacado el contexto en el que se encontraron las estatuas de la cueva Meunier en Saint-Martin-d'Ardeche, con dos figuras situadas a lado y lado de la entrada de la cueva, en el interior de la cual las excavaciones encontraron niveles sepulcrales con materiales del
Neolítico Final-Calcolítico. Con todo, los mismos investigadores no aseguran que los restos sepulcrales y las estelas puedan pertenecer a las mismas cronologías (Gilles 1988, Montjardin 1998).

Resulta muy interesante la interpretación que se hace desde una visión sociológica de las estelas de la necrópolis de Petit-Chasseur (Sion, Valais, Suiza), que forman junto a las estelas de la necrópolis de Saint-Martin-de-Corleans (Aosta, Italia) un grupo figurativo de gran entidad. En estos yacimientos encontramos algunas estelas in situ y otras reutilizadas para construir las cistas megalíticas. En el yacimiento suizo sus investigadores han interpretado las estelas como representaciones de personajes, donde el alzamiento y caída de las mismas podría tener tres explicaciones (Gallay 1995a, 110-112; 1995b, 185-186; 2006,101-103; 2009): 1.-erección de una estela para representar un individuo muerto y destrucción para representar su rechazo social; 2.-erección de una estela para consagrar o promocionar un individuo vivo y destrucción para representar su rechazo social; 3.-erección de una estela para consagrar o promocionar un individuo y destrucción por la muerte física del individuo. En los tres casos, una vez la estela ha sido tumbada y destruida se ha podido reutilizar para construir una nueva tumba megalítica.

En algunos lugares de la península ibérica estas figuras se han encontrado en puntos preeminentes dentro de recintos funerarios. En el caso del dolmen de Soto (Huelva) o algunas figuras del Alentejo estas imágeness llevan algún motivo interpretado como un arma o elemento de prestigio, lo que ha dado en interpretarse como símbolos de ancestros que justificarían la posesión de la tierra y del ganado por algunos grupos concretos. Esos símbolos colectivos serían convertidos y utilizados de forma individual por los jefes guerreros de sociedades jerarquizadas para justificar su posición preeminente. Esas comunidades justificarían su derecho a la propiedad de bienes comunes por medio de simbologías de tradición. Se servirían de la tradición y de los grafismos que permiten identificarlos para asociarse con las imágenes de los antepasados, convirtiéndose en herederos simbóli$\cos$ de esas representaciones. El utilizar estas figuras para marcar sus lugares de enterramiento y sus tierras, así como realizar rituales funerarios ostentatorios, reforzaría la unión con los antepasados que aseguraban la posesión de los bienes esenciales (Bueno et al. 2005). 
Desde una visión más sencilla pensamos que las estatuas-menhires podrían tener un claro simbolismo dentro del mundo religioso. Esta religión debía estar basada en el hecho de que estas divinidades podían rendir algunos servicios al hombre. De esta forma el hombre se descargaba de algunas responsabilidades, de algunas tareas no productivas: mientras los dioses guardaban las tumbas o guiaban a los viajeros, el pastor podía cuidar su ganado $\mathrm{y}$ el agricultor hacer la cosecha.

En el caso de la figura estudiada en este trabajo, sus enormes dimensiones nos han llevado a argumentar, en la línea de C. Tilley (1996), que esta gran figura debía ser un referente importante lleno de simbolismo en el paisaje de su entorno y que su alzamiento habría generado un gran prestigio y lucimiento al grupo social que la levantó. Esto mismo se ha argumentado para las grandes figuras de la Rouergue, donde podría existir una voluntad de ostentar su exposición (Maillé 2010).

Los datos de la investigación arqueológica y del estudio geológico de este yacimiento nos dicen que todo el espacio que ocupa el aparcamiento está situado en una terraza lateral del río Besós, situándose el mismo yacimiento en la confluencia de dos rieras (Riera de Gàllecs y Riera Seca) que desembocan en el mismo rio unos 500 metros más al sureste. La dinámica de funcionamiento de las dos rieras y la terraza lateral del Besós hacía que esta zona ocasionalmente se convirtiese en una zona inundable y quedase afectada por las corrientes del rio y las rieras, que en determinadas ocasiones, con episodios de torrentadas, podían ser muy violentas. Este hecho, testimoniado en los múltiples niveles de piedras, arenas, bloques,... que encontramos superpuestos en la estratigrafía del Pla de les Pruneres, nos lleva a argumentar que éste no sería un lugar con condiciones de hábitat en épocas prehistóricas.

Las dimensiones y el peso de la pieza $(4,90$ metros y $6.200 \mathrm{~kg}$ ) nos hacen pensar que, con todo, esta piedra no podía haber sido movida desde muy lejos. Estudiando el relieve de los alrededores del yacimiento, pensamos que la zona más indicada donde podría haber estado situada (clavada verticalmente) podría ser a tan solo 80-100 metros hacia el noroeste, en un espacio con una cota superior, fuera de las influencias de las rieras y posibles inundaciones.

Hemos podido recoger otros materiales en este yacimiento que, aunque no estaban "in situ", son testimonio de la presencia humana en las cercanías de este paraje desde hace miles de años. Todos estos materiales vienen arrastrados por las riadas, con posibles focos de origen hacia el noroeste del propio yacimiento.

\section{Agradecimientos}

Quiero agradecer el trabajo realizado por los compañeros/as arqueólogos/as Adriana Vilardell, Jordi Amorós, Aida Alarcos, Mireia Crespo y Víctor Heredia, que participaron en la excavación de este yacimiento tan poco agradecido y que demostraron siempre una gran profesionalidad y dedicación en su trabajo.

También a compañeros investigadores como Araceli Martín o Josep Tarrús, que son los grandes especialistas en Neolítico final y Megalitismo en Cataluña. Siempre pude contar con sus consejos, correcciones y aportaciones para trabajar yacimientos de estas cronologías y representaciones de arte megalítico como la presentada en este trabajo.

Quiero agradecer especialmente el apoyo recibido de muchos compañeros que en momentos de dificultades me mostraron su apoyo incondicional. Como arqueólogo profesional e investigador me he encontrado con un triste episodio que ha retratado a varias personas relacionadas con esta intervención. Aunque esto se ha convertido en una motivación para hacer este trabajo, considero innecesarias y muy tristes este tipo de motivaciones.

\section{Notas}

1. Términos geológicos con los que los geólogos describen los fragmentos de arcillas que, a causa de ser arrastradas por el agua, adoptan una morfología redondeada. Cuando estas bolas son únicamente de arcilla se denominan bolas blandas y cuando son arrastradas dentro de contextos de arenas y gravillas, estas bolas quedan rebozadas con estos materiales y pasan a llamarse bolas armadas.

2. Estudis de patrimoni històric. Universitat de Barcelona.

3. Comunicación personal de Jordi Bertran, geólogo y presidente del Centre d'Estudis Molletans. 


\section{REFERENCIAS BIBLIOGRÁFICAS}

AA.VV. (1994): La statuaria antropomorfa in Europa dal Neolitico alla romanizzazione. Atti del Congresso La Spezia-Pontremoli 1988, La Spezia.

Almagro-Gorbea, M. (1993): Les stèles anthropomorphes de la péninsule ibérique. Les représentations humaines du Néolithique a l'Age du Fer. 115 Congrès National des Sociétés Savantes, Avignon, Comité des Travaux Historiques et Scientifiques, París.

Anguas, F.; FÀBrega, A.; HuÉlamo, J.Ma ; Solias, J.Ma. (2006): Montpedrós Rock Art Bulletin. www.rupestre.net/ tracce $\mathrm{php} /$ modules.php? name $=$ News \& file $=$ article $\&$ sid $=42$

Ansó, J.; CAMPOY, G. (2007): A propòsit de la pedra salvadora. Notes, 22: 17-28.

Arnal, J. (1976): Les Statues-Menhirs, Hommes et Dieux, Ed. Des Hespérides, Toulouse.

Augusto, A. (1972): Corpus delle statue-stele Lunigianesi. Bordighera.

Bassols, I.; Farell, D.; Lleonart, R. (1995): Dòlmens. Una tradició funerària a Catalunya: el cas del Maresme. Col. Salusti, 2, Ed. Grup d'Història del Casal, Mataró.

Belley, A.M; Mezzena, F.; Renda, A.; ZidDA, G. (1998): Dei di Pietra. La grande statuaria antropomorfa nell'Europa del III Millenio a.C. Ginevra-Milano.

Blas Cortina, M.A. DE (1997): El arte megalítico en el territorio cantábrico: un fenómeno entre la nitidez y la ambigüedad. Brigantium, 10: 69-89.

BuEno RAmiREZ, P. (1990): Statues-menhirs et stèles anthropomorphes de la péninsule Ibérique. L'Anthropologie, 94: 85-110.

Bueno, P.; BAlbín, R. DE (2000): Tècniques, extensió geogràfica i cronologia de l'art megalític ibèric. El cas de Catalunya. Cota Zero, 16: 47-64.

Bueno, P.; BALbÍn, R. DE; BARroso, R. (2005): Hiérarchisation et métallurgie : statues armées dans la Péninsule Ibérique. L'Anthropologie, 109, 577-640.

Bueno, P.; BALbín, R. DE; BARroso, R. (2007): Chronologie de l'art mégalithique ibérique: C14 et contextes archéologiques. L'Anthropologie, 111: 590-654.

Bueno, P.; Balbín, R. DE; Barroso, R.; LóPez, J.C.; Guenaga, A. (2009): Frontières et art mégalithique. Une perspective depuis le monde pyrénéen. L'Anthropologie, 113: 882-929.

Bueno, P.; BARroso, R.; BAlbín, R. DE (2010): Metal and symbols of ancestors in Northern Iberia. Conceptualizing space and place: On the role of agency, memory and identity in the construction of space from the Upper Palaeolithic to the Iron Age in Europe (Bettencourt, A. M. S. et al., eds.), Archaeopress, BAR International Series 2058, Oxford: 71-87.

Corboud, P.; Curdy, P. (eds.) (2009): Stèles préhistoriques: la nécropole du Petit-Chasseur à Sion, Musées Cantonaux du Valais. Sion.

Cura, M. (1992): Són neolítiques les inscultures de Passanant? Estat de la investigació sobre el neolític a Catalunya. $9 e ̀$ Col-loqui Internacional d'Arqueologia de Puigcerdà, Servei d'Arqueologia d'Andorra. Andorra: 119-120.

CurA, M. (2002-2003): La "Pedra de Llinàs": un menhir, una estela o una fita de terme (Montmeló, Vallès Oriental, Catalunya). Quaderns de Prehistòria i Arqueologia de Castelló, 23: 133-139.

D'anna, A. (1977): Les Statues-Menhirs et Stèles Anthropomorphes du Midi Méditerranéen. C.N.R.S., París.

D'AnNA, A.; Renault, S. (eds.) (2004): Stèles anthropomorphes néolithiques de Provence. Catalogue du Musée Calvet d'Avignon. Établissement public Calvet, Avignon.

Fortó, A.; Martínez, P.; MuÑoz, V. (2005): L'estàtua-menhir antropomorfa de Ca 1'Estrada (Canovelles, Vallès Oriental). Cota zero, 20: 17-22.

ForTó, A.; Martínez, P.; MuÑoz, V. (2006): Ca l'Estrada (Canovelles, Vallès Oriental): un exemple d'ocupació de la plana vallesana des de la prehistòria a l'alta edat mitjana. Tribuna d'Arqueologia, 2004/2005: 45-70.

Fortó, A.; Martínez, P.; MuÑoz, V. (2007): Ca l'Estrada. Història de Canovelles 1, Museu de Granollers, Ajuntament de Canovelles, Granollers.

Fortó, A.; Martínez, P.; MuÑoz, V. (2008): La estatua-menhir de Ca l'Estrada. IV Congreso del Neolítico en la Península Ibérica, Alicante 2006 : 149-153.

Gallay, A. (1995a): La nécropole du Petit-Chasseur à Sion et ses stèles: idéologie et contexte social. Dans les Alpes, à l'aube du métal. Archéologie et bande dessinée (A. Gallay, ed.), Sion, Musées Cantonaux du Valais: 103-112.

Gallay, A. (1995b): Les stèles anthropomorphes du site mégalithique du Petit-Chasseur à Sion (Valais, Suisse). Statue-stele e massi incisi nell'Europa dell'Età del Rame (Casini, S., De Marinis, R. C., Pedrotti, A., eds.), Notizie Archeologiche Bergomensi 3: 167-194.

Gallay, A. (2006): Les sociétés mégalithiques. Pouvoir des hommes, mémoire des morts. Presses polytechniques et universitaires romandes, Le savoir Suisse, Laussanne. 
Gallay, A. (2009): Mise en valeur des découvertes du Petit-Chasseur et présentation au public. Les saisons du PetitChasseur (Mariethoz, F., ed.), Sion, Sedunum nostrum : 14.

Garcia, M.; Zaragoza, J.; Martín, J. (2003): La representación espiraliforme del fondo del aiguamoll (L'Abi, Les Garrigues, Lleida): Grafismo rupestre y simbologia. Revista d'arqueologia de Ponent, 13: 149-154.

GiLles, R. (1994): Les statues-menhirs du département de l'Ardèche, leur place dans le groupe bas-languedocien. La statuaria antropomorfa in Europa dal Neolitico alla romanizzazione. Atti del Congresso Internazionale La SpeziaPontremoli, 27 aprile-1 maggio 1988, La Spezia, Instituto Internazionale de Studi Liguri: 109-128.

GonçALVES, V.S. (2004): As deusas da noite: o projeto «Placa Nostra» e as placas de xisto gravadas da região de Évora. Revista Portuguesa de Arqueología, 7 (2): 49-72.

Grosjean, R. (1996): La Corse avant l'histoire. Klincksieck, París.

JiMÉneZ, J. (2006): La imagen de los espacios de alta montaña en la prehistoria: el caso de los Pirineos catalanes occidentales. www.recercat.net/bitstream/2072/12393/1/Binder1.pdf.

JORGE, S.-O. (1999): Un sanctuaire de la préhistoire récente de la péninsule ibérique avec des "Steles": Cabeço da Mina (Vila Flor au Portugal). L'Europe au temps d'Ulysse. Dieux et héros de l'âge du bronze, Conseil de 1'Europe, Copenhage.

LANDAU, J. (1977): Les représentacions anthropomorfes mégalitiques de la région méditerranéenne, (3e au ler millénaire). CNRS, París.

L'Helgouach, J. (1997): De la lumière aux ténèbres. Art et symboles du Mégalithisme européen. Revue Archéologique de 1'Ouest, supplément, 8.

Lopez, J.; Moya, A.; Escala, O.; Nieto, A. (2009): La cista tumular amb esteles esculpides dels Reguers de Seró (Artesa de Segre, Lleida): Una aportació insòlita dins de l'art megalític peninsular i europeu. Tribuna d'Arqueologia 2008: $87-126$.

MaILlÉ, M. (2010): Hommes et femmes de pierre. Statues-menhirs du Rouergue et du Haut-Languedoc. Archives d'Écologie Préhistorique, Toulouse.

Maluquer de Motes, J. (1971): La estela de la Edad del Bronce de Preixana (Lérida). Homenaje a D.José Esteban Uranga, Pamplona: 475-488.

Marfà, R. DE (2005): Monuments megalítics al Maresme sud. Quaderns de Natura i de l'Home, vol.2, nº6: 361-366.

Martin, A. (2003): Els grups del neolític final, calcolític i bronze antic. Els inicis de la metal·lúrgia. Cota zero, 18: 76-105.

Martin, A. (2006): La prehistòria al Baix Vallès. Notes, Mollet.

Martín, A.; Mestres, J.S. (2003): Periodització des de la fi del neolític fins a l'edat del bronze a la Catalunya sudpirinenca. Cronologia relativa i absoluta, Pirineus $i$ vë̈ns al $3 \mathrm{r}$ mil·lenni AC. De la fi del neolitic a l'edat del bronze entre l'Ebre i la Garona. XII Col-loqui Internacional d'Arqueologia de Puigcerdà, Institut d'Estudis Ceretans, Puigcerdà: 77-130.

MartínEZ, P. (2010): Estàtues-menhirs, testimonis d'una religió que va abastar tot Europa en el III mil·lenni aC. Notes: 149-184, Mollet.

Martínez, P.; Fortó, A.; Muñoz, V. (en prensa): La estatua-menhir de Ca l' Estrada (Canovelles, Barcelona) y los elementos figurativos del grupo de la Rouerge (Aveyron, Francia). Coloquio Internacional de Megalitismo, Beasain. Munibe $n^{\circ}$ 61, San Sebastián.

MontJardin, R. (1998): Menhirs et statues-menhirs en Ardèche. Archéologie en Languedoc 22, Actes du 2ème Colloque International sur la statuaire mégalithique (Sant-Pons-de-Thomières, du 10 au 14 septembre 1997): 197-205.

Moreau, E. (1970): Les pedres decorades de Passanant. Butlleti de la Societat Arqueologica de Tarragona, 69-70: 135-140.

Moya, A.; Martínez, P.; Lopez, J.B. (2010): Éssers de pedra. Estàtues-menhirs i esteles antropomorfes a l'art megalític de Catalunya. Cypsela, 18:11-41.

MÜLlER, D. (1996): Ornamente, symbole, bilder-zum megalithischen totenbrauchtum in mitteldeutschland. Art et symboles du Mégalithisme européen. Revue Archéologique de 1'Ouest, supplément nº 8: 163-176.

Palazón, J.A. (2010): Estudi geològic de la intervenció arqueològica del Pla de les Pruneres a Mollet del Vallès (Vallès Oriental). Informe inédito.

Philippon, A. (2002): Statues-Menhirs, des énigmes de pierre du fond des âges. Ed. Rouergue. Rodez.

PoRTEla, D.; JiMÉnEZ, J.C. (1996): Una nueva estela de guerrero. La estatua-menhir-estela de guerrero de Talavera de la Reina. Revista de Arqueología, 188: 36-43.

Ripoll, E.; BarberÀ, J.; Llongueras, M. (1965): Poblado de Puig Castellar (San Vicente dels Horts, Barcelona. Excavaciones Arqueológicas en España 40, Madrid.

RobB, J. (2009): People of Stone: Stelae, Personhood, and Society in Prehistoric Europe. Journal of Archaeology Method and Theory, 16(3): 162-183. 
Romero CArnicero, F. (1981): La estatua-menhir de Villar del Ala. Nuevos datos para su estudio. Numantia, 1: 115128.

Santonja Gómez, M.; Santonja Alonso, M. (1978): La estatua-menhir de Valdefuentes de Sangusín (Salamanca). Boletín de la Asociación Española de Amigos de la Arqueología, 10: 17-24.

Serra Vilaró, J. (1927): La civilització megalítica a Catalunya. Contribució al seu estudi. Musaeum Archaeologicum Diocesanum, Solsona.

SERRES, J. P. (1997): Les statues-menhirs du groupe Rouergat. Musée Archéologique de Montrozier, Guide d'archéo$\operatorname{logie} n^{\circ} 4$.

SHeE Twohing, E. (1981): The megalithic art of Western Europe. Oxford University Press, Oxford.

SpINDLER, K. (1995): El hombre de los Hielos. Círculo de Lectores, Madrid.

Tilley, C. (1996): An Ethnography of the Neolithic: Early Prehistoric Societies in Southern Scandinavia. Cambridge University Press, Cambridge.

TARRETE, J. (1997): L'art mégalithique dans le Bassin parisien; symétrie et latéralité dans les représentations du néolithique final. Revue archéologique de l'Ouest. Supplément.

TARrus, J. (2002): Dòlmens, poblats i menhirs. Els grups megalítics de l'Albera, Serra de Rodes $i$ Cap de creus. Barcelona.

VIDAL, M. (1911): Otros monumentos megalíticos en Cataluña. Memorias de la Real Academia de Ciencias y Artes de Barcelona 10/1, Barcelona, Reial Acadèmia de Ciències i Arts de Barcelona: 279-300.

Vilardell, R.; CAstells, J. (1976): Hallazgo de una estela decorada en el Pla de la Calma. Pyrenae, 12: $181-182$. 